\title{
Especialidades Médicas - Cirurgia de Cabeça e Pescoço
}

\author{
Marcos Roberto Tavares
}

\section{Histórico}

A cirurgia de Cabeça e Pescoço (CCP) é uma especialidade nova no Brasil e no mundo. Em 1847, Celius afirmou que "Quando um tumor de boca atinge a região submandibular, ele se torna incurável." Demorou quase 60 anos para que esta afirmação fosse retificada, quando no ano de 1906, Jorge Crile apresentou um trabalho sobre "Esvaziamento cervical". Em 1950, Hayes Martin apresentou melhores resultados com o tratamento sistemático. No Brasil, em 1981, por ações do Professor Alberto R. Ferraz, Professor Titular da Disciplina na FMUSP, a Cirurgia de Cabeça e Pescoço foi reconhecida no Brasil como Especialidade Médica.

\section{Abrangência}

É uma especialidade cirúrgica baseada na complexidade anatômica da face e pescoço. É voltada à oncologia, tratando dos tumores da mucosa do trato aéro-digestivo alto, das glândulas salivares, pele, ossos da face, tecidos de sustentação da face e pescoço. Faz também algumas reconstruções após ressecções.

Abrange também o tratamento de doenças benignas como as doenças da glândula tireóide, glândulas paratireóides, doenças congênitas como o cisto de ducto tireoglosso e doenças do aparelho branquial e tumores e malformações dos vasos linfáticos e sangüíneos como hemangiomas e linfangiomas e ainda tumores dos nervos, especialmente os schwanomas e neuroblastomas. Temo como área de atuação a Cirurgia Crânio-maxilo-facial, que divide com a Cirurgia Plástica e Otorrinolaringologia.
Por sua complexidade, o trabalho do cirurgião de cabeça e pescoço é eminentemente multidisciplinar. Vale-se das especialidades diagnósticas de Endoscopia, Radiologia, Patologia, Patologia clínica e Medicina Nuclear. Atua em conjunto com a Endocrinologia, Nefrologia, Radioterapia, Anestesiologia, Cirurgia Plástica, Neurocirurgia, Otorrinolaringologia, Oftalmologia, Oncologia e Hemoterapia. Tem também relações com outras áreas da saúde como a Fonoaudiologia, Psicologia e Fisioterapia, Odontologia, Nutrição, Serviço social e Enfermagem.

\section{Formação}

É uma especialidade Médica com atuação que transcende a técnica cirúrgica. Requer diagnóstico especializado, avaliação global do doente, escolha da opção terapêutica, conhecimento dos cuidados pré e pós-operatórios locais tanto regionais quanto sistêmicos e preparo para tratar complicações e sequelas estéticas e funcionais, muitas vezes, graves. Exige ainda conhecimento de oncologia.

É pré-requisito para a Residência em CCP a Residência Médica em Cirurgia Geral. O Programa de Residência Médica em CCP dura dois anos, com 8 horas diárias de atividade em Ambulatório, Enfermaria, UTI, Centro cirúrgico, Radiologia, Radioterapia e Endoscopia.

\section{Rotina}

A rotina do Cirurgião de Cabeça e Pescoço se divide entre consultório e centro cirúrgico, na maior parte do tempo com procedimentos eletivos, tendo também a opção de atendimento em pronto socorro, 
mormente para os que optam por atuar na Cirurgia Crânio-maxilo-facial.

Com exceção da tireóide, a maior parte dos casos de câncer tratado pela CCP está relacionado ao cigarro. O grande desafio do cirurgião é restabelecer os doentes à vida normal com qualidade. Boa parte dos portadores destas doenças é tratada no SUS. Embora seja difícil, é gratificante participar na recuperação de pessoas com maus hábitos de alimentação e higiene oral, muitos etilistas e tabagistas.

\section{Mercado de trabalho}

Ainda há campo de atuação para os egressos da especialidade. Com base na incidência e prevalência das doenças na população, estimamos que uma população de 150 mil habitantes comporte um Cirurgião de Cabeça e Pescoço atuando apenas da especialidade. Portanto é uma especialidade para centros mais desenvolvidos.

No Brasil os especialistas vinculados à Sociedade Brasileira de Cirurgia de Cabeça e Pescoço são apenas 557 (Quadro 1). O pequeno número de especialistas também no mundo facilita conhecer médicos em vários países, que frequentam os congressos internacionais, o que considero uma vantagem da especialidade.

Assim como outras especialidades cirúrgicas, a entrada no mercado de trabalho é gradual. Geralmente o recém-egresso participa como auxiliar numa equipe cirúrgica estabelecida cumpre plantões em Pronto Socorro e UTI, atende ambulatório geral e da especialidade, até que comece a ter seu próprio movimento. A remuneração acompanha a das demais áreas cirúrgicas, proporcional à intensidade de atuação.

\section{Dificuldades da Especialidade}

A formação é longa e, por ser especialidade ainda pouco conhecida, o profissional depende de encaminhamento de outros médicos e de pacientes previamente tratados por especialistas. Os procedimentos dependem também de hospitais com maior nível de complexidade e de equipes multidisciplinares. Por outro lado, esta dificuldade permite agradável convívio com profissionais de outras especialidades como cirurgia plástica, neurocirurgia, radioterapia, oncologia, otorrinolaringologia, oftalmologia, e também de fonoaudiologia, fisioterapia, psicologia e odontologia, entre outras.

Não é fácil se estabelecer nas grandes cidades que, em muitos casos, têm número de especialistas até acima do necessário.
Quadro 1. Distribuição dos especialistas no Brasil por estado

\begin{tabular}{|c|c|}
\hline Estado & Total \\
\hline Acre (AC) & 1 \\
\hline Alagoas (AL) & 2 \\
\hline Amazonas (AM) & 8 \\
\hline Bahia (BA) & 20 \\
\hline Ceará (CE) & 20 \\
\hline Distrito Federal (DF) & 13 \\
\hline Espirito Santo (ES) & 11 \\
\hline Goiás (GO) & 12 \\
\hline Maranhão (MA) & 9 \\
\hline Minas Gerais (MG) & 44 \\
\hline Mato Grosso do Sul (MS) & 6 \\
\hline Mato Grosso (MT) & 5 \\
\hline Pará (PA) & 6 \\
\hline Paraíba (PB) & 6 \\
\hline Pernambuco (PE) & 18 \\
\hline Piauí (PI) & 6 \\
\hline Paraná (PR) & 17 \\
\hline Rio de Janeiro (RJ) & 40 \\
\hline Rio Grande do Norte (RN) & 8 \\
\hline Rondônia (RO) & 3 \\
\hline Rio Grande do Sul (RS) & 19 \\
\hline Santa Catarina (SC) & 18 \\
\hline Sergipe (SE) & 4 \\
\hline São Paulo (SP) & 259 \\
\hline Tocantins (TO) & 2 \\
\hline Total & 557 \\
\hline
\end{tabular}

\section{Mitos e Preconceitos}

Um dos grandes mitos é o conflitos com outras especialidades, em especial a Otorrinolaringologia. A atuação não é competitiva e sim complementar. Muitos procedimentos dependem de formação específica, ora presente/ausente no cirurgião de cabeça e pescoço, ora no otorrinolaringologista. Alguns procedimentos podem ser realizados com igual competência por ambos especialistas. $\mathrm{Na}$ maior parte das vezes atuamos de forma conjunta e complementar.

A visão de ser uma especialidade que causa grandes prejuízos estéticos e funcionais nos doentes é também falsa. A título de exemplo, cito a laringectomia. Um procedimento com grave sequela, que é realizada na falta de alternativa para manter ou 
recuperar as funções de fonação e deglutição, que seriam perdidas pela evolução da doença. O cirurgião evita que a evolução da doença cause danos ainda maiores.

Em razão de eu estar formado há vários anos, para tentar melhor expressar a condição atual, repassei as perguntas (abaixo) a colegas especialistas formados nos últimos 5 anos no HCFMUSP: Rubens Aisawa, Caio Caliseo, Jorge Kim, Marialia Brescia, Sérgio Gonçalves.

\section{Perguntas:}

- Satisfação pessoal que a especialidade pode dar;

- Dificuldades da especialidade;

- Mercado de trabalho;

- Rotina;

- Salário (inicial, se estabiliza, se é pessoadependente);

- Preconceitos em relação à especialidade;

- Mitos.

\section{Depoimentos}

\section{Rubens Aisawa} a vida!.

Eu vou bem, trabalhando e tentando construir

Em relação ao solicitado, é um prazer poder ajudar!... No meu modo de ver as coisas, acho que a nossa especialidade nos ajuda a tratar de muitas pessoas que necessitam e não têm condições, principalmente no SUS. Estes pacientes, em grande parte das vezes, são etilistas, tabagistas e não têm bons hábitos de vida... É um campo difícil de trabalhar, mas que traz satisfação quando ajudamos o paciente a abandonar alguns vícios e a melhorar sua saúde como um todo. Ficamos muito tristes e preocupados quando não temos os materiais adequados disponíveis e sabemos que isso pode comprometer o resultado do nosso trabalho. E mesmo quando encaminhamos o paciente para o ICESP (nossa referência do HGIS) e demora tanto para ele ser efetivamente atendido... Sabemos que a culpa é do sistema, mas ainda assim, isso nos incomoda muito. Sem contar na equipe de apoio que não está acostumada com esses pacientes tão peculiares e acabam por não dar a devida importância para situações tão delicadas como um hematoma cervical. Já no consultório, o mais comum é tireóide, glândulas salivares, adenomegalias,... É outra realidade. Por outro lado, acho que a nossa colocação no mercado é facilitada pelos contatos adquiridos na residência e na faculdade. Porém, tenho alguns amigos da mesma especialidade que estão fora do mercado, não por falta de competência, mas por falta de alguém para "abrir as portas". Também, já passei pela experiência de não conseguir entrar em alguns grupos (por exemplo, no Santa Marcelina de Itaquaquecetuba) por tudo ser muito fechado, pelo bairrismo existente. O mercado de trabalho não é dos melhores, mas acho que a medicina está assim. É o que parece, quando converso com meus amigos. Realmente, acho que somos privilegiados por termos essa abertura.

A rotina faz parte de tudo, e acho que isso é bom. A nossa rotina é cirúrgica, bem melhor que ficar no consultório o dia todo!rs... Acho que $80 \%$ dos pacientes vêm com problemas na tireóide... E sempre há algo diferente... Acho muito bom ficar operando! O salário é compatível. Não acho ruim, mas também não acho bom demais. Acho razoável. Não sei quanto os colegas médicos ganham, mas cerca de cinco anos após a Residência, o rendimento mensal varia entre 15 e 25 mil. Para alguns está bom, enquanto para outros, talvez isso seja muito pouco.

A cirurgia de cabeça e pescoço é muito recente e muito desprestigiada por algumas pessoas. Sempre há a especialidade da moda e o resto. Muitos a consideram uma segunda opção. Nesta parte, não me incomodo. Estou bem satisfeito e tranquilo comigo mesmo.

Por fim, acho que o mais importante é ver se o possível candidato gosta dessa área. Se ele gostar, acho que ele deve pesar o que seria um bom salário para ele. Se estiver dentro da faixa do mercado, talvez seja uma boa escolha. Caso contrário, deverá pensar melhor... Foi o que eu fiz, e para mim, as coisas estão indo de acordo com o planejado!

\section{Jorge Kim}

\section{Satisfação pessoal que a especialidade pode dar}

Ainda há campo para atuação na especialidade.

Com a formação no HC, estamos preparados para resolver as principais doenças de nossa área. 